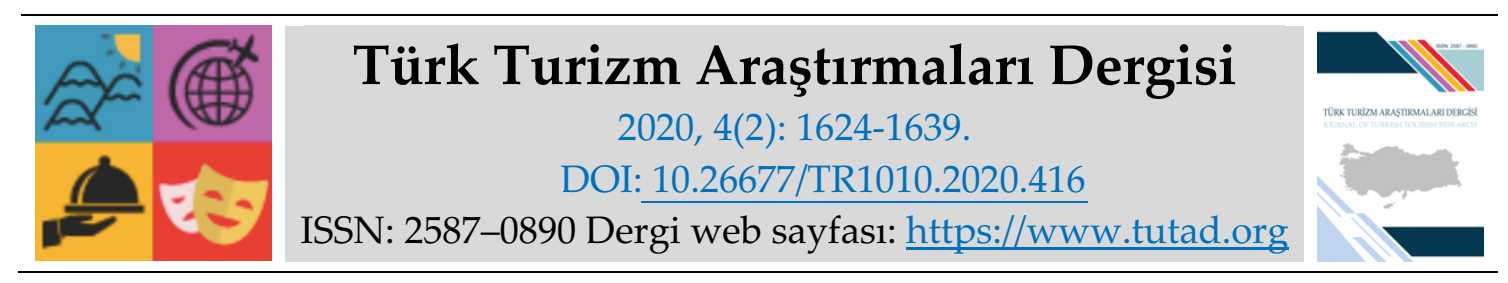

ARASTTIRMA MAKALESI

\title{
Sosyal Bilimlerde Paradigma İkilemi: Turizm Alanında Yazılmış Lisansüstü Tezler Üzerine Bir İnceleme
}

Dr. Öğr. Üyesi Özgür YAYLA, Akdeniz Üniversitesi, Manavgat Turizm Fakültesi, Antalya, e-posta: ozguryayla@akdeniz.edu.tr

ORCID: https://orcid.org/0000-0001-7124-9311

Dr. Öğr. Üyesi Gözde Seval ERGÜN, Akdeniz Üniversitesi, Manavgat Turizm Fakültesi, Antalya, e-posta: gates@akdeniz.edu.tr

ORCID: https://orcid.org/0000-0002-5697-626X

Öz

Bu çalışmada, turizm alanında yazılmış lisansüstü tezlerin bilimsel araştırma yöntemlerinde nicel yöntemlerden nitel yöntemlere geçişteki paradigmatik dönüşüm incelenmiştir. Çalışma amacına bağlı olarak YÖK ulusal tez merkezi veri tabanında 'turizm ve işletme', 'gastronomi', 'rekreasyon ve yönetim' 'seyahat ve acente', 'turizm ve rehberlik' anahtar kelimeleri kullanılarak tarama yapılmış ve ulaşılan 107 adet tez değerlendirmeye tabi tutulmuştur. Araştırma kapsamında nitel ve nicel araştırma yöntemleri bir arada kullanılmış, nitel kapsamda doküman incelemesi ve nicel araştırma kapsamında ise çoklu uyum analizinden faydalanılmıştır. Araştırma sonucunda pozitivist paradigmanın turizmde yazılan lisansüstü tezlerde egemen olduğu sonucuna ulaşılmıştır. Ayrıca, 2010 yılından itibaren yazılan tezlerde nitel yöntemlerde artış yaşandığı, rekreasyon yönetimi alanındaki tezlerde ağırlıklı olarak nitel yöntemler kullanılırken, turizm işletmeciliği, seyahat işletmeciliği ve turizm rehberliği ile gastronomi ve mutfak sanatları alanlarında daha çok nicel ve karma yöntemlerin kullanıldığı tespit edilmiştir.

Anahtar Kelimeler: Paradigma, Pozitivizm, Post-Pozitivizm, Turizm, Tez.

Makale Gönderme Tarihi: 01.02.2020

Makale Kabul Tarihi: 15.04 .2020

\section{Önerilen Atıf:}

Yayla, Ö. ve Ergün, G. S. (2020). Sosyal Bilimlerde Paradigma İkilemi: Turizm Alanında Yazılmış Lisansüstü Tezler Üzerine Bir İnceleme, Türk Turizm Araştırmaları Dergisi, 4(2): 1624-1639.

(c) 2020 Türk Turizm Araştırmaları Dergisi. 


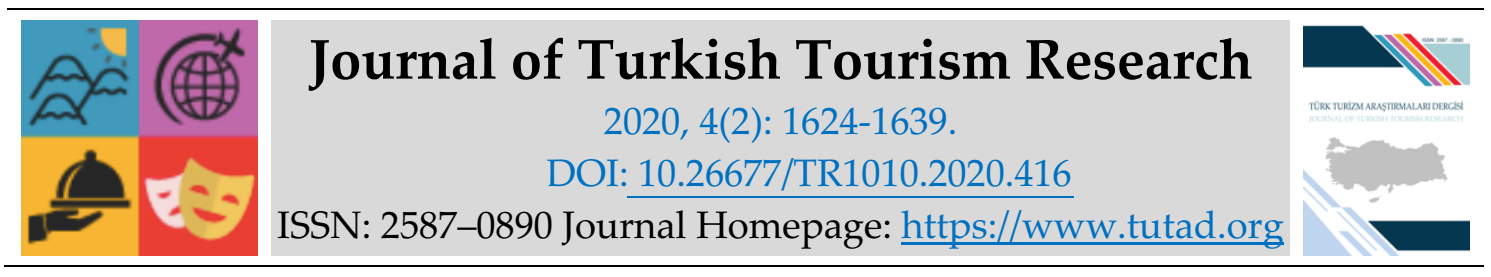

RESEARCH PAPER

\title{
Paradigm Dilemma in Social Sciences: A Study on Postgraduate Dissertations Written in the Field
}

Assistant Prof. Dr. Özgür YAYLA, Akdeniz University, Manavgat Faculty of Tourism, Antalya, e-mail: ozguryayla@akdeniz.edu.tr ORCID: https://orcid.org/0000-0001-7124-9311

Assistant Prof. Dr. Gözde Seval ERGÜN, Akdeniz University, Manavgat Faculty of Tourism, Antalya, e-mail: gates@akdeniz.edu.tr ORCID: https://orcid.org/0000-0002-5697-626X

\begin{abstract}
In this study, the paradigmatic transformation of postgraduate dissertations written in the field of tourism from the quantitative methods to the qualitative methods in the scientific research methods has been examined. Depending on the purpose of the study, a research has been conducted in the National Thesis Center Database of Council of Higher Education (YÖK) through the keywords of "tourism and business", "gastronomy", "recreation and management", "travel and agency", "tourism and guidance" and 107 dissertations reached have been evaluated. Qualitative and quantitative research methods were used together within the scope of the research, and document analysis in the qualitative scope and multiple compliance analysis were used within the scope of the quantitative research. At the end of the research, it has been observed that the positivist paradigm is dominant in postgraduate dissertations written in the field of tourism. In addition, it has been determined that the use of qualitative methods have increased in the dissertations written since 2010; while qualitative methods have mostly been used in the dissertations written in the field of recreation management, quantitative and mixed methods have been used in the fields of tourism management, travel management and tourism guidance, and gastronomy.
\end{abstract}

Keywords: Paradigm, Positivism, Post-Positivism, Tourism, Thesis.

Received: 01.02.2020

Accepted: 15.04 .2020

\section{Suggested Citation:}

Yayla, Ö. and Ergün, G. S. (2020). Paradigm Dilemma in Social Sciences: A Study on Postgraduate Dissertations Written in the Field, Journal of Turkish Tourism Research, 4(2): 1624-1639.

(c) 2020 Türk Turizm Araştırmaları Dergisi. 


\section{GİRIŞ}

Modern bilim, başlangıçtan bugüne kadar uzunca bir dönem için pozitivist paradigmanın kontrolü altında kalmıştır. Her ne kadar pozitivist bilim felsefesine alternatif sayılabilecek yaklaşımların eski dönemlere uzandığı bilinse de modern bilimin metodolojisi üzerinde etkileri sınırlı kalmıştır. Günümüzde, yalnızca sosyal bilimler alanında değil, doğa bilimlerinde de pozitivist yaklaşımın eleştirildiği ve alternatif yaklaşımların ön plana çıkarıldığı paradigmatik bir dönüşümün varlığından söz etmek mümkündür (Kuş, 2007).

Fen bilimleri gibi sosyal bilimler araştırmaları da genellikle çalışmanın güvenilirliğini ve genellenebilirliğini artırmak amacıyla bir araştırma paradigmasının benimsenmesini gerektirmektedir. Araştırma paradigmalarının uygulanmasının, araştırmacının seçimine ve araştırılan konunun karakterine bağlı olarak bir araştırmacıdan diğerine değiştiği bilinmektedir. Araştırma paradigmalarının uygulanmasındaki farklılıklar, sadece felsefi varsayımlara değil, aynı zamanda araştırmanın sonuçlarına ve elde edilen bulguların yorumlanmasına da bağlı olmaktadır. Paradigmalar, araştırılan olguyu ve araştırmanın yürütülme şeklini tanımlayarak çalışmanın doğası üzerinde etkili olmaktadır.

Geçmişten beri süregelen şekilde hem fen bilimlerinde hem de sosyal bilimlerde yaygın olarak kullanılan araştırma yöntemlerinin 'nicel araştırma yöntemleri' olduğu bilinmektedir. Bununla beraber anket araştırması, deney metodu gibi nicel araştırma yöntemlerinin pozitivist paradigmadan oldukça etkilendiği görülebilmektedir (Yıldırım, 1999). Sosyal bilimler alanında, nicel araştırma geleneğinden nitel araştırma geleneğine geçiş, pozitivist paradigmadan postpozitivist paradigmaya doğru bir dönüşüm içinde değerlendirilmektedir. Bundan yola çıarak sosyal bilimler alanında dünya geneline bakıldığında son 25 yıldır nitel araştırmaların düzenli bir şekilde artış gösterdiği görülmektedir (Kuş, 2007).

Dünyada bilim üretiminin en büyük kaynağının üniversiteler olduğu bilinmektedir. Akademisyenlerin ortaya koyduğu bilimsel araştırmalara ek olarak lisansüstü eğitimin en büyük çıtıları olan tezler de bu bilim üretiminin bir parçası olarak görülmelidir. Araştırmada, YÖK Ulusal Tez Merkezi veri tabanında belirli kısıtlar altında taranan, turizm alanında yazılmış lisansüstü tezlerin yöntemlerinin paradigmik dönüşüm çerçevesinde incelemelerinin yapılması amaçlanmaktadır. Ayrıca bu araştırmanın, okuyuculardaki nitel / post-pozitivist ve nicel / pozitivist terimleri arasındaki mevcut kavramsal karışıklığın giderilmesini de sağlayacağı düşünülmektedir.

\section{PARADIGGM KAVRAMI}

Paradigma kelimesinin etimolojik analizine bakıldığında Latince "paradigma" kelimesinden geldiği ve Yunancada "paradeigma" olarak kullanıldığı görülmektedir (Kankam, 2019). Paradigma kavramının ilk olarak, Thomas Kuhn tarafindan yazılan ve 1962'de yayımlanan "Bilimsel Deorimlerin Yapısı" adlı eserde kullanıldığı bilinmektedir (Kuhn, 1995).

Araştırma paradigması bilimsel araştırmalarda doğru uygulandığında, araştırmacıların ilgilendikleri bir olguyu net bir şekilde araştırmasına olanak tanımakta ve böylece bilimsel araştırma yürütülürken zihinsel ve düşünsel bir ortam sağlanmaktadır (Kankam 2019). Bu bağlamda, araştırma paradigmaları "araştırmacının dünyaya baktığı zihinsel pencereyi" temsil etmektedir (Bailey, 1982). Literatürde paradigma kavramını anlatan birbirinden farklı ve birbirini tamamlayan birçok tanım göze çarpmaktadır.

Araştırma paradigması, katılımcı grup için gerçekliği göz önünde tutmanın bir yolunu oluşturan bir dizi varsayım, kavram, uygulama ve değer anlamına gelmektedir (McGregor ve Murnane, 
2010). Babbie (2014) paradigmaların bilimde temel bir rol oynadıklarını iddia etmekte, Jackson (2003) ise paradigmayı "belirli bir bilimsel topluluğun faaliyetini şekillendiren ve yönlendiren fikir, varsayım ve inançlar" şeklinde tanımlamaktadır. Yine aynı eserinde Babbie (2014) araştırma paradigmalarını "gördüklerimizi ve onları nasıl anladığımızı şekillendiren gözleme ve anlama modelleri veya çerçeveleri" olarak tanımlamaktadır. Bir başka tanımda ise, araştırma paradigmasının kapsayıcı bir inanç sistemi, dünya görüşü ve "bir alandaki araştırma ve uygulamayı etkileyen çerçeve" olduğu söylenmektedir (Willis, 2007). Kısacası, bir teoriden farklı olarak teorik çerçeveye paradigma denilmekte (Mertens, 2005) ve bu kavram bilginin incelenme ve yorumlanma şeklini etkilemektedir (Mackenzie ve Knipe, 2006).

\section{POZITIVIST PARADIGMA}

Pozitivizm, gerçeğin gözlemciden bağımsız olduğu doktrini üzerine kurulmuş, kendi kendini yöneten, bağımsız ve gerçeğin nesnel varlığını anlatan bir araştırma paradigmasıdır (Aliyu vd., 2014). Aristoteles, Francis Bacon, August Comte ve Emmanuel Kant kaynaklı rasyonel, ampirist felsefeye dayandırılan pozitivizm, bazen 'bilimsel yöntem' veya 'bilim araştırması' olarak da adlandırılmaktadır (Mackenzie ve Knipe, 2006; Mertens, 2005).

19. yüzyıldan itibaren modern bilimin gelişiminde pozitivist paradigmanın etkisinin büyük olduğu görülmektedir. Bu dönemde Auguste Comte başta olmak üzere Émile Durkheim gibi bilim insanlarının yaklaşımları, sosyal bilimlerin pozitivist paradigmanın egemenliğini kabul etmesine öncü olmaktadır (Yüce vd., 2014). Comte'un çalışmaları sonucunda sosyal bilimlerde de yerini bulan pozitivizm, temelde doğa bilimlerine özgü olan yaklaşımların ve bilimsel çatının sosyal bilimlere aktarılmak istenmesinin bir sonucu olarak da görülmektedir (Demir, 2019). Bazı kaynaklara göre 200 yıl önceye dayanan bir terim olan pozitivist araştırma paradigması, bilginin doğru olabilmesinin tek yolunun bilimsel yöntem kullanılarak yaratılmış olmasını yani ampirik metodolojiyi kapsamakta, verilerin deney ve gözlem yoluyla elde edildiğini anlatmaktadır (McGregor ve Murnane, 2010).

Aliyu vd., (2014) çalışmalarında, pozitivist araştırmacılar tarafından sıkça kullanılan metodolojilerin doğrulayıcı analiz, nomotetik deneyler, nicel analiz, laboratuvar deneyleri ve tümdengelim yöntemlerini içerdiğini ileri sürmüştür. Pozitivistler ayrıca "tüm fenomenlerin gerçeği temsil eden ampirik göstergelere indirgenebileceğini" savunmakta (Sale ve Brazil, 2004) ve "bilimsel gerçeklerin ampirik gözlemler ile gözlemlenenlerin mantıksal analizi yoluyla doğrulanabileceğine" inanmaktadır (Babbie, 2014). Bunlarla beraber, pozitivist paradigmanın bir teoriyi test etmeyi ya da "bizi çevreleyen kuvvetleri tahmin etmek ve kontrol etmek için gözlem ve ölçüm yoluyla" bir deneyimi tanımlamayı amaçladığı da bilinmektedir (Mackenzie ve Knipe, 2006).

20. yüzyıla kadar olan dönemde ve sosyal bilimlerin gelişmesi sürecinde araştırmacılar çalışmalarını pozitivist paradigmanın hakimiyetinde gerçekleştirmişlerdir. Bunun en önemli sebebinin sözü geçen dönemde başka bir paradigma varlı̆̆ından bahsetmenin mümkün olmaması ve bu durumun bilim çevrelerinde olağan karşılanması olduğu söylenmektedir (Yıldırım ve Şimşek, 2016).

\section{POST-POZITIVIST PARADIGGA}

Post-positivizm, İkinci Dünya Savaşı'ndan sonra pozitivizmin yerini almaya başlamıştır. Postpozitivizmin doğuşunun, pozitivist epistemolojik/metodolojik varsayımların reddi ve 
memnuniyetsizliğiyle başladığı iddia edilmekte (Eun, 2016) bununla beraber sezgisel, bütünsel, tümevarımsal ve nitel bulgularla birlikte keşifsel olduğu da ileri sürülmektedir (O'Leary, 2004).

1960'lı yılların ortalarında ortaya çıkan bir terim olan post-pozitivist araştırma paradigması, bilimsel yöntemi kullanmanın yanı sıra bilmenin birçok yolu olduğunu da varsaymaktadır. Postpozitif paradigmayı temel alan araştırmalar, hipotezi test etmek yerine, tümevarımsal akıl yürütme yoluyla hipotezler üretmektedir. Bu yaklaşımda araştırmacılar, bir şeyin nasıl işlediğini açıklamak yerine insan davranışlarının nasıl şekillendiğini anlamaya veya güç ilişkilerini ve yapılarını ortaya çıkarmaya çalışmaktadır (McGregor ve Murnane, 2010).

O'Leary (2004)'e göre post-positivistler dünyayı, gerçeklik kavramı göz önüne alındığında belirsiz, değişken ve çoklu olarak görmektedirler. Post-pozitivizm, "Bir kişi veya kültürel grup için "doğru" olan nedir? Bu doğru, diğer bir kişi ya da grup için "doğru" sayılabilir mi? sorularına da cevap aramaktadır. Post-pozitivist yaklaşımda, insanlar, araştırma sürecinden soyutlanmamakta aksine araştırma sürecinin merkezi olarak görülmektedirler. Bu paradigma içinde, deneysel ortamlardan ziyade topluluklarda ve insanların günlük yaşamlarında araştırmalar yapılması önerilmektedir. Post-pozitivist araştırmalar genellikle modeller oluşturulmasını, altta yatan yapıların keşfedilmesini, inançların, benzerliklerin, yaşam biçimlerinin, ideolojilerin ve güç ilişkilerinin ortaya çıkarılmasını amaçlamaktadır (McGregor ve Murnane, 2010).

Post-pozitivistler araştırmalarını büyük ölçekli olmaktan ziyade küçük gruplar üzerinde gerçekleştirmektedirler. Burada amaç, her şey ve herkes için geçerli genel yasalar belirlemek yerine belirli kültürel ve sosyal bağlamlarda anlam ve/veya güç aramaktır. Bu nedenle ne araştırmacının ne de katılımcıların pozitivist paradigmada olduğu gibi tarafsız kalamadıkları da söylenmektedir (McGregor ve Murnane, 2010). Post-pozitivizm kavraminın literatürde yorumlayıcı paradigma, eleştirel paradigma ve post-modern paradigma gibi farklı kavramlarla da açıklandığı görülmektedir.

Sosyal bilimler temelli araştırma yöntemlerinde geçmişten günümüze devam eden pozitivist eğilim, matematik temelli ve karmaşık istatistik yöntemlerinin kullanımını uzmanlık göstergesi sayarak bir norm ya da amaç haline getirmiştir. Sosyal vakaların nicel incelemelere tabi tutulması ve daha da ötesinde araştırmacıların bu yöntemlerin uygulanmasında başarılı olduklarını gösterme çabasıyla araştırma yapmaları, yöntem seçimi ile ilgili tartışmaları ve şüpheleri de beraberinde getirmiştir (Dedeoğlu, 2002: 76). Araştırmacıların genel olarak keşfedici araştırmalardan kaçınmakta olduğu ve nitel araştırma eğiliminde olmadıkları görülmektedir. Bu durumun, akademisyenlerin nitel araştırma yöntemlerine yeterince hâkim olmamasından ve yayın çıkarma endişesinden kaynaklandığı düşünülmektedir (Kurtuluş, 2002). Bryman (1988)'in "araştırmacılar genellikle belirli araştırma tarzlarında eğitildikleri için, diğer yaklaşımlara olan eğilimleri, öğrenme istek ve yetenekleri sınırlı kalmaktadır" sözleri de bu durumu destekler niteliktedir (Khoo-Lattimore vd., 2019). Psikoloji, sosyoloji, felsefe gibi temel sosyal bilimlerde ortaya çıkan tartışmalarla, sosyal bilimler ile doğa bilimlerini benzer şekilde inceleme ve matematiğe dayalı yöntemler kullanarak tek doğruya ulaşma yönündeki girişimlere şüpheyle bakılmaya başlanmıştır (Dedeoğlu, 2002: 77).

Pozitivist ve post-pozitivist paradigma arasında temel farklar bulunmaktadır. Lincoln ve Guba (2000: 170-171)'ya göre pozitivizm saf gerçekçilik üzerine kafa yormaktadır. Buna göre "gerçek" gerçeklik kavranabilirdir. Buna karşın post-pozitivizmin, eleştirel gerçeklik üzerinde durduğu görülmektedir. Yani "gerçek" gerçeklik ancak olasılığa dayalı ve kusurlu olarak kavranabilirdir. Epistemolojik açıdan bakıldığında ise pozitivist paradigmaya göre bulgular doğrudur ve gerçeğe götürmektedir. Post-pozitivist paradigma ise bulguların muhtemelen doğru olduğunu söylemektedir. Yıldırım ve Şimşek (2016)'e göre pozitivist paradigma gerçekliğin basit, değişimin 
nicel olduğunu ve birikimli ilerlediğini söylemektedir. Ayrıca nedensellik ilişkisi bilindiği takdirde bu ilişkinin sonuçlarının da açıklanabildiğini iddia etmektedir. Post-pozitivist paradigmada ise gerçekliğin karmaşık olduğuna inanılmakta ve ilişkilerin yönünün tam olarak kestirilemeyeceği iddia edilmektedir. Bununla beraber karşılıklı nedenselliğin mevcut olduğu düşünülmekte ve gözlemcinin bakış açısının önemi vurgulanmaktadır.

\section{SOSYAL BILIIMLERDE NICEL VE NITTEL YÖNTEMLER}

Bilimsel araştırma, bir eğitimsel veya psikolojik fenomeni “anlamak, tanımlamak, tahmin etmek veya kontrol etmek ya da bu bağlamdaki bireyleri güçlendirmek amacıyla verilerin bir şekilde toplandığı, analiz edildiği ve yorumlandığı bir sistematik veya soruşturma" olarak tanımlanmaktadır (Mertens, 2005). Araştırmanın amacını, motivasyonunu ve beklentilerini ortaya koyan şey paradigma seçimidir. Bu nedenle, araştırmanın ilk adımını bir paradigma tayin edilmesi oluşturmalıdır. Paradigma belirlenmemesi metodoloji, yöntemler, literatür veya araştırma tasarımı ile ilgili daha sonraki seçimler için bir temel oluşmamasına sebep olacaktır (Mackenzie ve Knipe, 2006).

Tablo 1. Araştırma Tasarım Süreci

\begin{tabular}{|c|c|c|}
\hline Araştırmanın Unsurları & Araştırma Yaklaşımları & Araştırma Süreci \\
\hline \multicolumn{3}{|l|}{ Alternatif Bilgi Talebi } \\
\hline \multirow[t]{3}{*}{ (Epistemoloji) } & & Araştırma Sorusu \\
\hline & & Teorik Altyapı \\
\hline & Nicel & Veri Toplama \\
\hline \multirow[t]{3}{*}{ Araştırma Stratejileri } & Nitel & Verilerin Analizi \\
\hline & Karma Yöntem & Raporlama \\
\hline & & Değerlendirme \\
\hline
\end{tabular}

Kavramsallaştırma

Uygulamaya Dönüştürme

Kaynak: Creswell, (2003: 5).

Araştırma tasarım sürecinin ayrıntılı olarak gösterildiği Tablo 1'e göre bir araştırma teklifi tasarlanırken, araştırma bilgisini şekillendiren epistemolojik varsayımın, metodolojinin arkasında yatan teorik perspektifin, yöntem seçimini yöneten metodolojinin, kullanılan tekniklerin ve prosedürlerin dikkate alınması gerektiği öne sürülmektedir (Creswell, 2003).

Literatürde pozitivist paradigma ile nicel araştırmaların, post-pozitivist ve yorumlayıcı paradigma ile de nitel araştırmaların eşleştirildiği görülmektedir (Lin, 1998). Nicel araştırmalarda en çok tercih edilen yöntemin anket toplama olduğu bilinmektedir. Odak grup görüşmeleri, vaka analizleri, uzman kişilere başvurma gibi keşfedici araştırmalara (Gegez, 2007) yer verilmeden, sadece literatür taramasıyla yön verilen anket araştırmalarında her ne kadar derecelendirmeye 
olanak veren ifadeler ya da açık uçlu sorulara yer verilse de araştırmacının sunduğu alternatifler ve ifade kısıtı sebebiyle ölçülmeye çalışılan davranışı/tutumun altında yatan nedenleri tespit etme olanağı zayıf kalmaktadır. Özellikle katılımcıya teslim edilerek doldurulduktan sonra geri alınan anket uygulamalarında, sorularda sıralama sapmaları meydana gelmektedir. Bunun sonucunda katılımcı cevap vermeden önce tüm ifadelerde göz gezdirmekte böylece anketin neyi ölçtüğü hakkında genel bir kanıya varmakta ve ifadeleri ona göre cevaplamaktadır. Bu gibi durumlar kişinin gerçek fikrinden ziyade kendisinden istenen ya da toplum tarafından kabul görecek şekilde anketin doldurmasına sebebiyet vermektedir. Örneğin; cep telefonu kullanım amacı ile ilgili bir araştırma yapıldığında, bireylerin yüksek fiyatlı telefonları gösteriş amaçlı kullandığı gözlemlense de kullanıcılara sorulduğunda mobil iletişim amaçlı satın alma yapıldığı yanıtının alınması muhtemel görünmektedir. Bu nedenle bu tür anket çalışmalarında bireyin, davranışını belirli bir mantığa büründürmek için olduğundan farklı önermelere yönelebileceği düşünülmektedir (Dedeoğlu, 2002).

Nitel araştırma kavramı ise, doğal yollarla ortaya çıkan olguların frekansını değil, anlamını tanımlamak, kodunu çözmek, tercüme etmek veya başka türlü ifade etmek isteyen bir dizi yorumlayıcı tekniği kapsayan bir şemsiye terim olarak kullanılmaktadır (Shah ve Corley, 2006). Nitel araştırmaları bu şekilde tarif etmek mümkün görünse de herkes tarafından kabul edilmiş bir tanımını yapmak güçtür. Bunun nedeni ise bu şemsiye terimin altına dahil edilebilecek birçok kavramın farklı disiplinlerle de ilişkili olmasından kaynaklanmaktadır. Bununla beraber nitel araştırma "gözlem, görüşme, doküman analizi gibi nitel veri toplama yöntemlerinin kullanıldığı algıların ve olayların gerçekçi ve bütüncül bir şekilde ortaya konmasına yönelik bir sürecin izlendiği bir araştırma yöntemidir" şeklinde tanımlanabilir (Yıldırım ve Şimşek, 2016).

Nitel araştırmanın sosyoloji, antropoloji psikoloji, felsefe gibi çeşitli disiplinlere dayanan güçlü teorik altyapısı bulunmaktadır. Sözü edilen disiplinlerde ortak amaç bireyin davranışını doğal ortamı içinde çok yönlü olarak anlamaya çalışmaktır. Bu disiplinlerin penceresinden bakıldı̆̆ında, insan davranışının fen bilimlerinde göz önüne alınan değişkenlerden farklı algılanması gerekmektedir. Bu sebeple sosyal bilimler alanındaki araştırmalarda nicel yöntemlerin dışında insan davranışının doğasına uygun nitel yöntemlerin geliştirilmesi gerektiğine işaret edilmektedir. Bir araştırmacının hangi yöntemi kullanacağı araştırmanın amacına, çalışılacak grubun ve ortamın özelliklerine göre değişiklik gösterecektir. Bu nedenle bazı araştırmalarda birden fazla yaklaşıma yer vermek çeşitli anlayışları birlikte kullanmak gerekmektedir (Yıldırım ve Şimşek, 2016). Nitel ve nicel veriler arasındaki suni seçimden vazgeçen sosyal bilimciler, daha ziyade her ikisinin en değerli özelliklerini kullanan kombinasyonlarla ilgilenmektedirler. Burada sorun, hangi noktada hangi yaklaşımın benimsenmesi gerektiğinin belirlenmesidir (Merton, 1987).

Lincoln ve Guba (2000), pozitivist ve post-pozitivist dünya görüşleri arasında paradigmatik veya felsefi düzeyde ölçülebilirliğin mümkün olmadığını ancak her paradigma içinde, karma metodolojilerin son derece mantıklı olabileceğini savunmaktadırlar. Aslında, çoğu bilim insanı nicel araştırma (sayısal analiz ve ölçümler) ve nitel araştırma (duygular, algılar ve anlamlar) yöntemlerini kullanmanın ve bunları aynı araştırma projesinde bir araya getirmenin önemini bilmektedir (McGregor ve Murnane, 2010). Tüm araştırma yöntemlerinde olduğu gibi karma araştırma deseninin de çeşitli avantajları ve dezavantajları vardır. Karma yöntem kullanmanın para ve zaman maliyeti doğurması gibi zayıf yönlerinin yanında oldukça güçlü yönleri de bulunmaktadır. Örneğin, farklı veri toplama yöntemlerinin kombinasyonunun, tek bir yöntem araştırmasının zayıflıklarını en aza indirmeye yardımcı olacağı söylenebilmektedir (KhooLattimore vd., 2019). 
Karma yöntem araştırmalarının, temel avantajı, nitel ve nicel yaklaşımları entegre ederek, araştırma sorunlarına daha derin kavrayışlar sağlaması ve karmaşık sosyal meseleleri her iki yaklaşımdan da daha iyi anlamaya yardımcı olmasıdır. Karma yöntem uygulanmasını öneren bilim çevreleri, günümüz dünyasında sosyal sorunların daha karmaşık, birbiriyle bağlantılı olduğunu ve çoğu zaman birbiriyle etkileşen sistemleri (örneğin iklim değişikliği, terörizm, sosyal eşitsizlik) içerdiğini savunmaktadırlar (Truong vd., 2020). Yöntemin uygulanmasındaki en önemli engellerden biri ise, araştırmacıların hem nitel hem de nicel yöntemler hakkında bilgi sahibi olmasını gerektirmesidir. Ancak çoğu bilim insanı sadece bir yöntem üzerinde uzmanlığa sahip olma eğilimindedir (Molina-Azorín, 2012).

Araştırma tasarımlarında karma yöntemlerin kullanımının turizm alanında da özellikle son yıllarda önem kazandığı görülmektedir. Dünya genelinde turizm literatürü tarandığında aynı araştırma projesinde hem nicel hem de nitel teknikleri kullanan çok sayıda çalışma örneğine rastlamak mümkün olmaktadır (Heimtun ve Morgan, 2012; Singh vd., 2012; Tutenges, 2012; Molina-Azorín, 2012). Truong vd., (2020)'nin en çok atıf alan sekiz turizm ve otelcilik dergisini inceledikleri çalışmalarında karma yöntem tercih edilerek yapılan araştırmaların yıllar itibariyle önem kazandığını tespit etmişlerdir. Araştırma sonuçlarına göre 1998-2002 yılları arasında 64 (\% 8,5); 2003-2007 döneminde 120 (\% 15,9); 2008-2012 yılları arasında 207 (\% 27,5) ve son dönemde (2013-2017) 362 (\% 48,1) makalede karma yöntem uygulandığı görülmüştür. Yine aynı çalışmada, sözü edilen dergilerde yayımlanan nicel (1998-2002, 688; 2003-2007, 992; 2008-2012, 1424; 20132017, 3317) ve nitel (1998-2002, 354; 2003-2007, 421; 2008-2012, 597; 2013-2017, 1044) araştırma sayılarının da yıllar itibariyle arttı̆̆ görülmektedir.

Turizm literatüründe araştırma yöntem seçimlerinde dünya genelinde görülen eğilim ile Türkiye'de yapılan akademik araştırmaların yönünün tespitinin ve kıyaslanmasının, akademik altyapı ve yönelim anlamında araştırmacılara ışı tutacağı düşünülmektedir. Bu nedenle çalışmada, zaman kısıtı olmaksızın Türkiye'deki turizm ile ilgili anabilim dallarından çıkan lisansüstü tezlerin yöntem bakımından incelenmesi amaçlanmıştır. Sonucunda ise; turizmde araştırma yöntemlerinin kullanımı ve dünya turizm literatürünün neresinde bulunulduğu ile ilgili bir durum tespitine ulaşılmak istenmektedir.

\section{YÖNTEM}

$\mathrm{Bu}$ araştırmada nitel ve nicel araştırma yöntemleri bir arada kullanılmıştır. Araştırma kapsamında doküman incelemesi tekniğinden yararlanılmış olup, YÖK Ulusal Tez Merkezi veri tabanındaki turizm alanında yazılan lisansüstü tezler yazıldığı alan, yıl, tür, yöntem ve çalışma konusu olarak incelenmiştir. Elde edilen veriler kategorik içerik analizi tekniğiyle değerlendirilmiştir. İçerik analizinde benzer veriler belirli temalar çerçevesinde bir araya getirilerek incelenmektedir (Bauer, 2003; Cohen vd., 2007). Turizm anabilim dalında yazılan tüm tezlerin incelenmesinin gerek zaman kısıtı gerekse doğrudan turizm ve yakın ilişkili olduğu alanlarda yazılan spesifik çalışmaların tespiti amacıyla, veri tabanında belli anahtar kelimeler kullanarak genel bir tarama yapılmıştır. Anahtar kelimeler tespit edilirken turizm fakültelerinde var olan 4 farklı anabilim dalı isimleri tercih edilerek konuya yönelik daha spesifik teze ulaşılması amaçlanmıştır. Yapılan ilk taramada 'turizm ve işletme' 'gastronomi', 'rekreasyon ve yönetim' 'seyahat ve acente' anahtar kelimeleri kullanılmış ve sonucunda 98 adet lisansüstü çalışma tespit edilmiştir. Öte yandan seyahat acenteciliği ve turizm rehberliği programlarına yönelik olarak 'turizm ve rehberlik' anahtar kelimesi kullanılarak ikinci bir tarama daha yapılmış ve ulaşılan 9 lisansüstü tez araştırma kapsamında dahil edilmiştir. Özetle, doküman incelemesinin odak noktası, turizmin temel araştırma konusu olarak ele alındığı çalışmaların incelenmesi olmuştur. Yıl açısından herhangi bir sınırlandırma yapılmamış olup, Ocak 2020 ayına kadar geçen süredeki 
tüm zaman aralığı inceleme kapsamına alınmıştır. Sonuç olarak 5 farklı anahtar kelime kullanılarak yapılan taramada 107 adet çalışmaya ulaşılmıştır. Ulaşılan tüm çalışmalar araştırma amacına bağlı olarak incelenerek SPSS'e aktarılmış ve tezlere ait betimsel bulguların tespitinde yüzde, frekans tablolarından faydalanılmıştır. Bunun yanında, tezler arasında ilişkilerin belirlenebilmesi amacıyla, kategorik hale getirilmiş sürekli değişkenlerin, daha az boyutlu bir uzayda grafiksel olarak gösterimi sağlayan çok değişkenli analiz yöntemi olan (Özdamar, 2004) çoklu uyum analizi kullanılmıştır.

\section{BULGULAR}

Araştırma kapsamında incelenen lisansüstü tezlere ilişkin bilgiler Tablo 2' de yer almaktadır. Tezin yazıldığı alan dahilinde veriler incelendiğinde var olan dört temel bölümde de sayıların birbirine yakın olduğu görülmektedir.

Tablo 2. Verilerin Yüzdesel Dağılımı (n:107)

\begin{tabular}{|c|c|c|c|}
\hline & & $\mathbf{n}$ & $\%$ \\
\hline \multirow{4}{*}{ Tezin yazıldığı alan } & Turizm İşletmeciliği & 20 & 18,7 \\
\hline & Seyahat İşletmeciliği ve Turizm Rehberliği & 29 & 27,1 \\
\hline & Rekreasyon Yönetimi & 27 & 25,2 \\
\hline & Gastronomi ve Mutfak Sanatları & 31 & 29,0 \\
\hline \multirow{3}{*}{ Tezin yazıldığı yıl } & 2000 yılı ve öncesi & 5 & 4,7 \\
\hline & 2001-2009 & 30 & 28,0 \\
\hline & 2010-2019 & 72 & 67,3 \\
\hline \multirow{2}{*}{ Tezin Türü } & Yüksek lisans & 92 & 86,0 \\
\hline & Doktora & 15 & 14,0 \\
\hline \multirow{3}{*}{ Tezin Yöntemi } & Nitel & 37 & 34,6 \\
\hline & Nicel & 62 & 57,9 \\
\hline & Karma & 8 & 7,5 \\
\hline \multirow{9}{*}{ Çalışılan konu } & Destinasyon pazarlaması & 31 & 29,0 \\
\hline & Bölgesel kalkınma & 21 & 19,6 \\
\hline & Turizm eğitimi & 6 & 5,6 \\
\hline & Tanitım & 10 & 9,3 \\
\hline & İşletme yönetimi & 24 & 22,4 \\
\hline & Sürdürülebilirlik & 4 & 3,7 \\
\hline & Sektörel sorunlar & 5 & 4,7 \\
\hline & Tüketici davranışları & 4 & 3,7 \\
\hline & Diğer & 2 & 1,9 \\
\hline
\end{tabular}

Tezlerin çalışıldığı yıllar itibariyle değerlendirildiğinde ise son yıllarda bir artış göze çarpmaktadır. Öyle ki, tezlerin \% 4,7'si 2000 yılından önce çalışılırken bu oran 2001-2009 yılları arasında \% 28, 2010-2019 yılları arasında ise \% 67,3 olduğu tespit edilmiştir. Ayrıca, tezlerin 
ağırlıklı olarak yüksek lisans tezlerinden oluştuğu söylenebilir (\% 86). Bunun yanında, metodolojik olarak incelenmesi sonucunda lisansüstü tezlerin yarısından fazlasının nicel yöntemleri kullandığı söylenebilir. Bu oran nitel araştırmalarda \% 34,6 olarak belirlenmiştir. İlgili alanda yazılan tezlerin yalnızca \% 7,5'inde karma yöntem tercih edilmiştir. Lisansüstü tezlerde çalışılan konuların dağılımları göz önünde bulundurulduğunda ise ağırlıklı olarak destinasyon pazarlaması, işletme yönetimi ve bölgesel kalkınma gibi konuların çalışıldığı tespit edilmiştir.

Tablo 3. Bölüm, Çalışılan Konu, Yöntem ve Yıl Değişkenlerinin Ayrışım Ölçüleri

\begin{tabular}{lll}
\hline Değişkenler & \multicolumn{2}{l}{ Boyutlar } \\
\cline { 2 - 3 } & $\mathbf{1}$ & $\mathbf{2}$ \\
\hline Bölüm &, 662 &, 795 \\
\hline Çalışılan konu &, 631 &, 752 \\
\hline Yöntem &, 281 &, 011 \\
\hline Yıl &, 430 &, 228 \\
\hline
\end{tabular}

Tablo 3'de değerlendirilen lisansüstü tezlerin bölüm, çalışılan konu, yöntem ve yıl değişkenleri kapsamındaki ayrışım ölçüleri görülmektedir. Tablo 3 incelendiğinde yöntem ve yılın birinci boyutun, bölüm ve çalışılan konunun ise ikinci boyutun açıklanmasında daha fazla katkıda bulunduğu tespit edilmiştir.

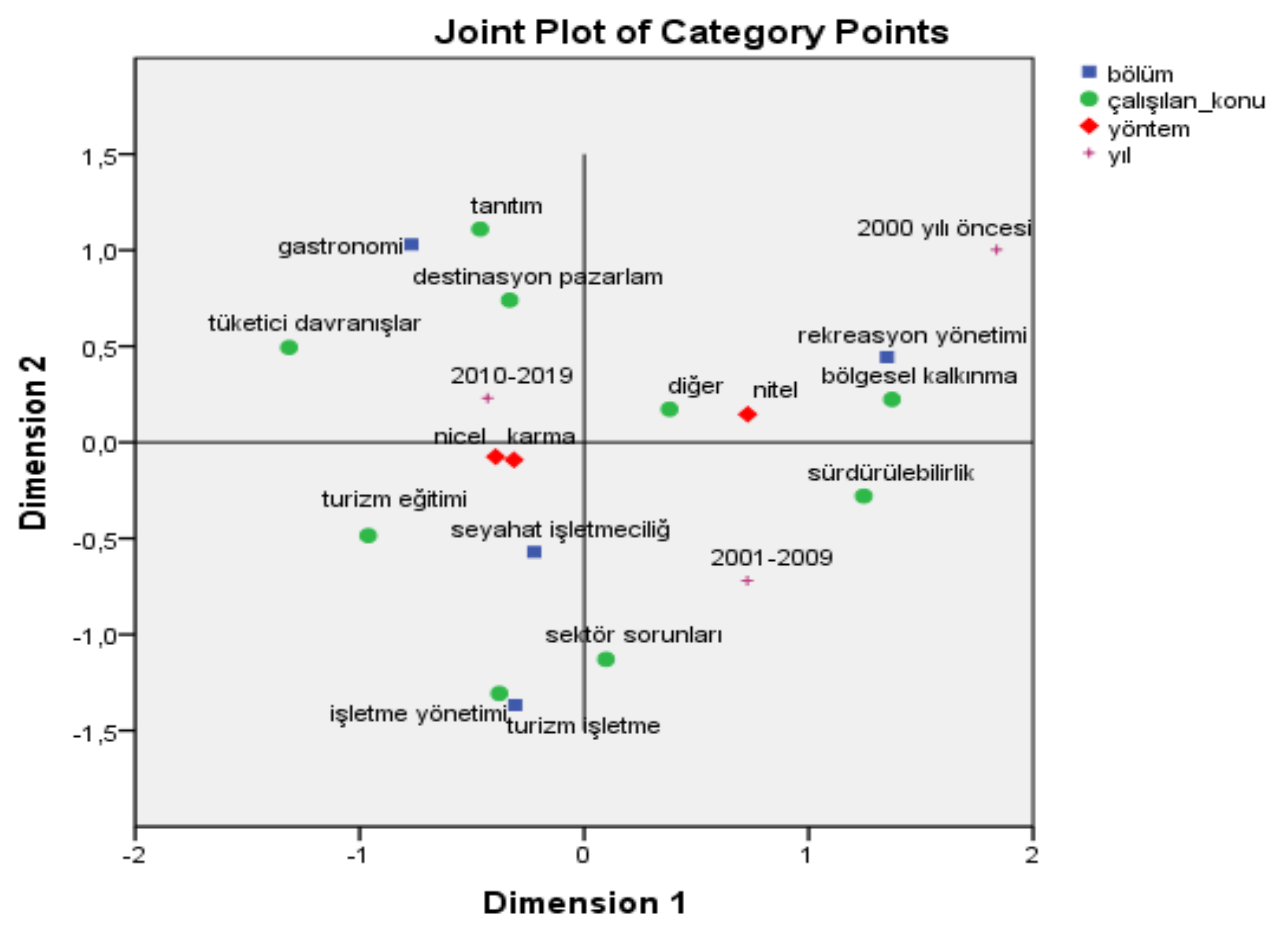

Variable Principal Normalization.

Şekil 1. Bölüm, Çalışılan Konu, Yöntem ve Yıl Değişkenlerinin Uyum Analizi

Şekil 1'de turizm alanında yazılan lisansüstü tezlerin bölüm, çalışılan konu, yöntem ve yazıldıkları yıllar değerlendirmeye tutularak gerçekleştirilen çoklu uyum analizi sonuçları yer almaktadır. Sonuçlar incelendiğinde turizm işletmeciliği alanında yazılan tezlerin genel olarak 
işletme yönetimi ve sektörel sorunlar alanında yoğunlaştığı görülmektedir. Seyahat işletmeciliği alanında yazılan tezlerin ise genel olarak turizm eğitimine yönelik gerçekleştirilmiştir. Bunun yanında seyahat işletmeciliği ve turizm rehberliği alanında yoğun olarak nicel ve karma yöntemler tercih edilmiştir. Nitel yöntemin en fazla tercih edildiği rekreasyon yönetimi alanında yazılan tezlerde ise ağırlıklı olarak bölgesel kalkınma ve sürdürülebilirlik konuları çalışıldığı tespit edilmiştir. 2010 yılından sonra daha sık çalışılan alanlardan biri haline geldiği görülen gastronomi ve mutfak sanatları lisansüstü tezlerinde ise tüketici davranışları, tanıtım ve destinasyon pazarlaması gibi pazarlama ağırlıklı konular çalışıldığı söylenebilir.

Tablo 4. Bölüm, Nitel Yöntem ve Yıl Değişkenlerinin Ayrışım Ölçüleri

\begin{tabular}{lll}
\hline Değişkenler & \multicolumn{2}{l}{ Boyutlar } \\
\cline { 2 - 3 } & $\mathbf{1}$ & $\mathbf{2}$ \\
\hline Bölüm &, 692 &, 009 \\
\hline Nitel Yöntem &, 601 &, 692 \\
\hline Y11 &, 623 &, 733 \\
\hline
\end{tabular}

Nitel yöntemlerin kullanıldığı lisansüstü tezler, bölüm ve yıl kapsamındaki ayrışım ölçüleri ile incelenmiş ve sonuçları Tablo 4'de gösterilmiştir. Tablo 4 incelendiğinde bölüm değişkeninin birinci boyutu, nitel yöntem ve yıl değişkenlerinin de ikinci boyutu açılamasında daha fazla katkıda bulunduğu tespit edilmiştir.

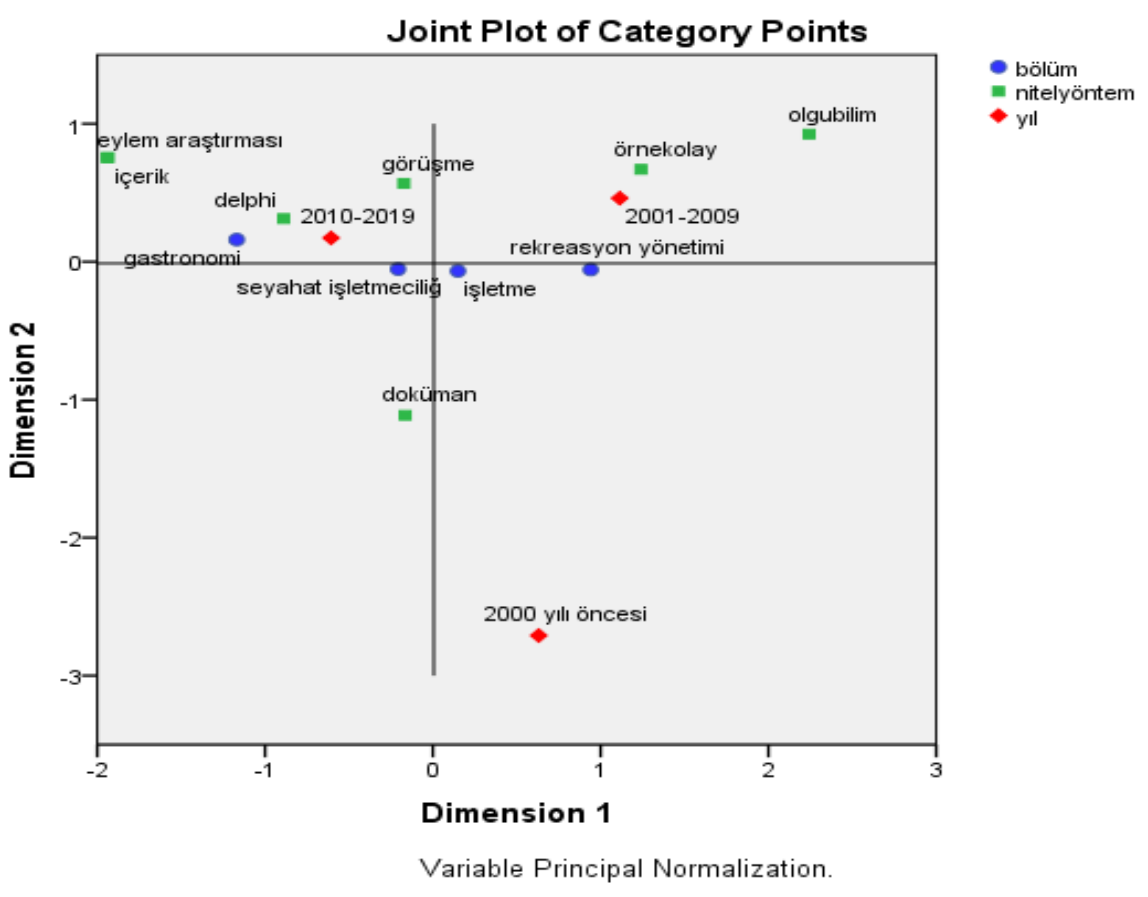

Şekil 2. Nitel Yöntem Kullanılan Tezlerdeki Bölüm ve Yıl Değişkenlerinin Uyum Analizi

Turizm alanında yazılan ve nitel araştırma yöntemi kullanılan 45 adet lisansüstü tezin, bölüm ve yazıldıkları yıllar ile birlikte değerlendirmeye tutularak gerçekleştirilen çoklu uyum analizi sonuçları Şekil 2'de yer almaktadır. Şekil 2'de nitel yöntemlerin son yıllarda daha fazla tercih 
edildiği görülmektedir. Zira, 2000 yılı ve öncesinde nitel araştırma yöntemini kullanan herhangi bir çalışmaya rastlanmazken, 2010 ve 2019 yılları arasında nitel araştırmalarda bir artış tespit edilmiştir. Bunun yanında rekreasyon yönetimi alanında yazılan lisansüstü tezlerde ağırlıklı olarak örnek olay ve olgubilim yöntemi tercih edilirken, gastronomi ve mutfak sanatları, turizm işletmeciliği ile seyahat işletmeciliği ve turizm rehberliği alanında ise görüşme, Delphi yöntemi, içerik analizi ve eylem araştırması gibi yöntemlerin daha fazla tercih edildiği söylenebilir.

Tablo 5. Bölüm, Nicel Yöntem ve Yıl Değişkenlerinin Ayrışım Ölçüleri

\begin{tabular}{lll}
\hline Değişkenler & \multicolumn{2}{l}{ Boyutlar } \\
\cline { 2 - 3 } & $\mathbf{1}$ & $\mathbf{2}$ \\
\hline Bölüm &, 711 &, 581 \\
\hline Nicel Yöntem &, 574 &, 277 \\
\hline Y1l &, 393 &, 602 \\
\hline
\end{tabular}

Nicel yöntemlerin kullanıldığı lisansüstü tezler, bölüm ve tez türü kapsamındaki ayrışım ölçüleri ile incelenmiş ve sonuçları Tablo 5 'de yer almaktadır. Tablo 5 incelendiğinde bölüm ve nicel yöntem değişkenlerinin birinci boyutu, yıl değişkeninin de ikinci boyutu açıklamasında daha fazla katkıda bulunduğu tespit edilmiştir.

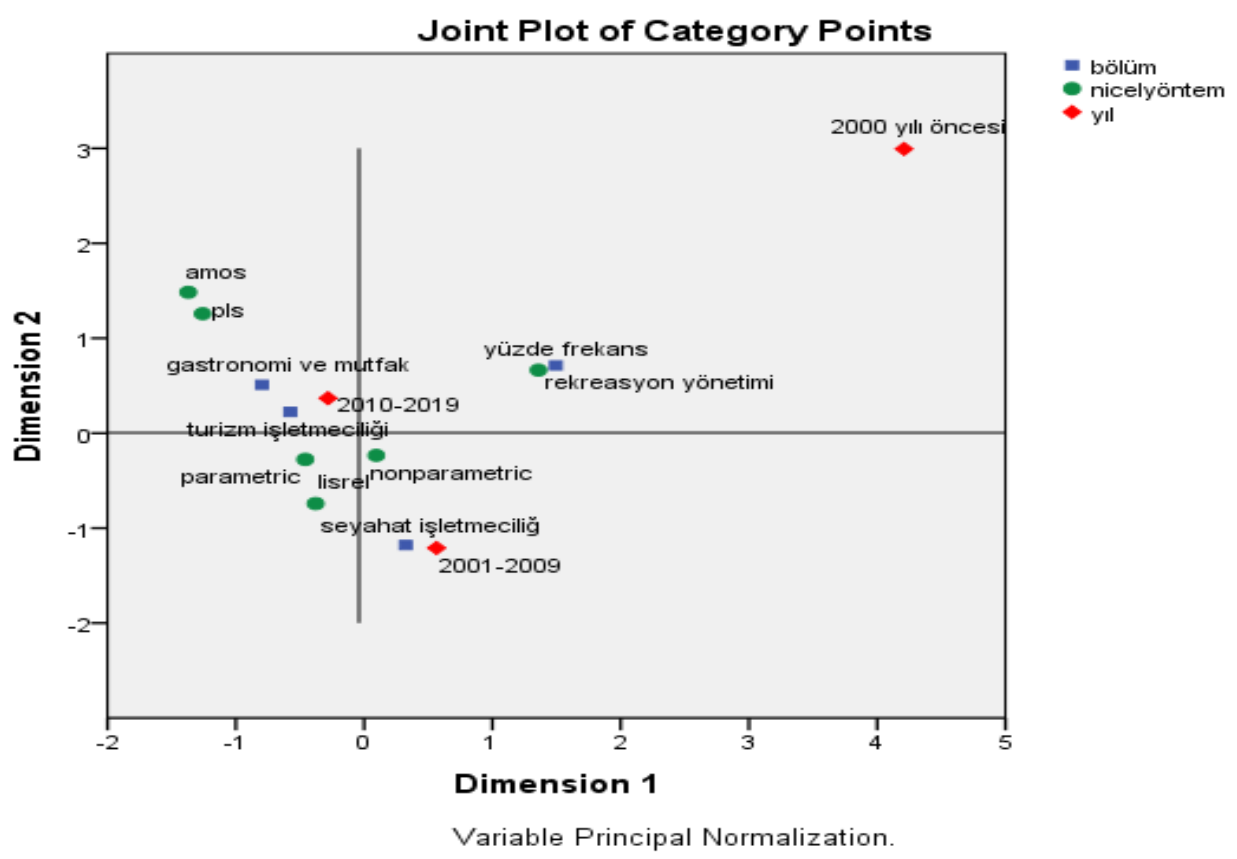

Şekil 3. Nicel Yöntem Kullanılan Tezlerdeki Bölüm ve Yıl Değişkenlerinin Uyum Analizi

Nicel araştırma yöntemlerinin kullanıldığı 70 adet lisansüstü tez, bölüm ve yıl değişkenlerine göre çoklu uyum analizi ile incelenmiş, sonuçları Şekil 3'te gösterilmiştir. Sonuçlar değerlendirildiğinde rekreasyon yönetimi alanında yazılan tezlerde ağırlıklı olarak yüzde, frekans verileri tercih edilirken, parametrik, nonparametrik testler turizm işletmeciliği ile seyahat işletmeciliği ve turizm rehberliği alanında yoğun olarak kullanıldığı tespit edilmiştir. Ayrıca, 
nicel yöntemlerde SPSS'e alternatif olarak kullanılan AMOS ya da Smart PLS gibi programların turizm işletmeciliği ve gastronomi ve mutfak sanatları alanında yazılan lisansüstü tezlerde daha fazla tercih edildiği görülmektedir.

Araştırmada incelenen turizm alanına yönelik yazılan lisansüstü tezler, pozitivist ve postpoizitivist paradigma kapsamında değerlendirilmiştir. Çoklu uyum analizi sonucunda lisansüstü tezlerde her ne kadar 2010 yılından itibaren postpozitivist paradigmada artış yaşansa da daha çok pozitivist paradigmanın egemen olduğu, bununla birlikte en fazla destinasyon pazarlaması, işletme yönetimi ve bölgesel kalkınma konularının çalışıldığı söylenebilir.

\section{SONUÇ VE TARTIŞMA}

$\mathrm{Bu}$ araştırma, turizm temalı lisansüstü tezlerin pozitivist ve post-pozitivist paradigma dönüşümlerinin incelenmesi amaciyla belirlenen 107 adet lisansüstü tez üzerinden yürütülmüştür. Böylece, Türkiye'de YÖK tez veri tabanında yayımlanan turizmle ilişkili tezlerin söz konusu dönüşümün neresinde olduğu belirlenerek mevcut iki paradigmanın karşılaştırmalı araştırma eğilimleri değerlendirilmiştir.

Yapılan araştırma sonucunda, Türkiye'deki turizm alanında yazılan lisansüstü çalışmalarda pozitivist paradigmanın daha yoğun olduğunu söylemek mümkündür. Zira, tezlerin \%60'a yakınının nicel yöntem kullanılarak kurgulandığı, 2010 yılından itibaren bir artış olmasına rağmen, nitel yöntem kullanılarak yazılan tezlerin \%35 oranında olduğu, bunun yanında örneklem olarak incelenen tezlerin yalnızca \%7,5'inin nicel ve nitel yöntemleri birlikte kullandığ 1 tespit edilmiştir. Çıvak ve Sezerel (2018) turizm araştırmalarında kullanılan paradigmaları tespit etmek üzere hakemli dergilerde yayımlanan 326 makalede pozitivist paradigmanın araştırmalarda sıklıkla tercih edildiğini saptamışlardır. Kutanis vd., (2007) ise yönetim organizasyon alanında yapılan lisansüstü tezlerde kullanılan paradigmaları incelemek amacıyla yaptıkları çalışmada yüksek lisans düzeyinde nicel, doktora düzeyinde ise nitel ve nicel yöntemlerin bir arada kullanıldığı sonucuna ulaşmışlardır. Benzer şekilde, Yüce vd. (2014)'nin dilbilimi alanında yazılan doktora tezlerine yönelik yaptığı incelemede pozitivist paradigmanın yüksek oranda tercih edildiği saptanmıştır. Literatürde ulaşılan sonuçlar mevcut çalışma sonuçları ile paralellik göstermektedir. Bu durum, post-pozitivist paradigmanın amaç ve desen açısından çeşitlilik sağlaması ile bilgi üretimindeki zenginliğin arttırılması açılarından oldukça önemli görülmesine rağmen (Arı vd., 2009) sosyal bilimler alanındaki nitel araştırmalara yönelik eğitimlerin yeterli olmaması ile açıklanabilir. Zira, Kutanis vd., (2007) Türkiye'deki 10 farklı üniversitenin lisansüstü programlarına yönelik yaptıkları çalışmada yalnızca bir tane devlet üniversitesinde nitel araştırma yöntemleri dersinin bulunduğu sonucuna ulaşmışlardır. Bunun yanında Ekiz (2004) Türkiye'de bireye duyulan güven sorunundan dolayı dergi editörlerinin ve akademisyenlerin nitel araştırmaları manipüleye açık ve etik dışı olarak algılamalarına neden olduğunu iddia etmektedir.

Yazılan tezlerin bölümlerine göre dağılımları değerlendirildiğinde ise nitel yöntemler en fazla rekreasyon yönetimi alanında, nicel ve karma yöntemler ise seyahat işletmeciliği ve turizm rehberliği alanlarında tercih edilmiştir. Nitel çalışmalarda daha çok turizm ve bölgesel kalkınma temalı konular incelenirken nicel ve karma yöntemlerin kullanıldığ çalışmalarda en fazla turizm eğitimine yönelik sorunların incelendiği tespit edilmiştir.

Çalışmada elde edilen önemli sonuçlardan bir diğeri ise bölümler bazında kullanılan nitel ve nicel yöntemlerin içeriğidir. Kutanis vd., (2007)'nin yönetim alanında 610 bildiri üzerinde yapmış oldukları çalışmada bildirilerde en çok kullanılan nitel araştırma yöntemlerinin sırasıyla içerik/betimsel analiz, örnek olay olduğu, metafor/söylem analizi, sözlü tarih, hayat hikayesi, 
odak grup görüşmeleri olduğu, veri toplama yöntemi olarak ise en çok mülakatın tercih edildiği belirtilmektedir. $\mathrm{Bu}$ çalışmada ise, nitel araştırmalarda, rekreasyon yönetimi alanındaki lisansüstü tezlerde daha çok örnek olay ve olgubilim yöntemi tercih edilirken, gastronomi ve mutfak sanatları, turizm işletmeciliği ile seyahat işletmeciliği ve turizm rehberliği alanında ise görüşme, Delphi yöntemi, içerik analizi ve eylem araştırması yöntemleri kullanılmıştır. Nicel yöntemlerin kullanıldığı tezlerde ise, rekreasyon yönetimi alanında ağırlıklı olarak yüzde, frekans verileri kullanılırken, parametrik, nonparametrik testler turizm işletmeciliği ile seyahat işletmeciliği ve turizm rehberliği alanında, yapısal eşitlik modellemelerinin ise gastronomi ve mutfak sanatları alanında yoğun olarak kullanıldığı tespit edilmiştir.

Bu çalışma YÖK tez veri tabanında beş farklı anahtar kelime kullanılarak taranan turizm alanında yazılan 107 adet lisansüstü tez ile sınırlıdır. İleride yapılacak olan çalışmalarda turizm alanında yayımlanan uluslararası tezlerin ve Türkiye'de söz konusu alanda yayımlanan makalelerin incelenerek sonuçlarının bu çalışma sonuçları ile mukayese edilmesi araştırma paradigmalarının bütüncül bir görünümünün sağlanması ve literatürün ulaştığı somut bilgi birikiminin arttırılması açısından önem arz etmektedir.

\section{KAYNAKÇA}

Aliyu, A. A., Bello, M. U., Kasim, R., and Martin D. (2014). Positivist and Non-Positivist Paradigm in Social Science Research: Conflicting Paradigms or Perfect Partners? Journal of Management and Sustainability, 4 (3): 79-95.

Arı, G. S., Armutlu, C., Tosunoğlu, N. G. ve Toy, B. Y. (2009). Pozitivist ve Postpozitivist Paradigmalar Çerçevesinde Metodoloji Tartışmalarının Yönetim ve Pazarlama Alanlarına Yansımaları, Hacettepe Üniversitesi İktisadi ve İdari Bilimler Fakültesi Dergisi, 27 (1): 113-141.

Babbie, E. (2014). The Basics of Social Research (6th ed.). Belmont, CA: Wadsworth.

Bailey, K. D. (1982). Methods of Social Research (2nd ed.). New York, NY: The Free Press.

Bryman, A. (1988). Quantity and Quality in Social Research. London: Unwin Hyman.

Bauer, M. W. (2003). Classical Content Analysis: A review, Bauer, M. W. and Gaskell G. (Eds.), Qualitative Researching with Text, Image and Sound (pp. 131-151). London: Sage Publications.

Creswell, J. W. (2003). Research Design: Qualitative, Quantitative, and Mixed Method Approaches. United States of America: Sage Publications.

Cohen, L., Manion, L., and Morrison, K. (2007). Research Methods in Education. New York, NY: Routledge.

Çıvak, B. ve Sezerel, H. (2018). Araştırma Paradigmaları ve Turizm Yazını, Turizm Akademik Dergisi, 5 (1): 1-14.

Dedeoğlu, A. Ö. (2002). Tüketici Davranışları Alanında Kalitatif Araştırmaların Önemi ve Multidisipliner Yaklaşımlar. D.E.Ü.İ.I.B.F.Dergisi, 17 (2): 75-92.

Demir, E. (2019). Bilimsel Araştırma Paradigmaları. Ders Notları, Ankara Üniversitesi, Ankara.

Ekiz, D. (2004). Eğitim Dünyasının Nitel Araştırma Paradigmasıyla İncelenmesi: Doğal ya da Yapay. Türk Eğitim Bilimleri Dergisi, 4 (2): 415-439.

Eun, Y. S. (2016). To What Extentis Post-Positivism 'Practised' in International Relations? Evidence from China and the USA. International Political Science Review, 38 (5): 1-15.

Gegez, E. (2007). Pazarlama Araştırmaları. İstanbul: Beta Yayıncılık. 
Heimtun, B., and Morgan, N. (2012). Proposing Paradigm Peace: Mixed Methods in Feminist Tourism Research. Tourist Studies, 12 (3): 287-304.

Jackson, M. C. (2003). Systems Thinking. Chichester, England: Wiley.

Khoo-Lattimore, C., Mura, P., and Yung, R. (2019). The Time Has Come: A Systematic Literature Review of Mixed Methods Research in Tourism, Current Issues in Tourism, 22 (13): 1531-1550.

Kankam, P. K. (2019). The Use of Paradigms in Information Research. Library and Information Science Research, 41: 85-92.

Kurtuluş, K. (2002). Ülkemizdeki Akademik Amaçlı Pazarlama Araştırmalarına İlişkin Bir Değerleme ve Öneriler, 7. Ulusal Pazarlama Kongresi, Afyon.

Kuhn, T.S. (1995). Bilimsel Devrimlerin Yapısı (Çeviren, Kuyaş, N.). İstanbul: Alan Yayıncılık.

Kuş, E. (2007). Sosyal Bilim Metodolojisinde Paradigma Dönüşümü ve Psikolojide Nitel Araştırma. Türk Psikoloji Yazıları, 10 (20): 19-41.

Kutanis, R. Ö., Bayraktaroğlu, S. ve Yıldırım, E. (2007). Nitel Araştırmanın Dayanılmaz Hafifliği-2 İdealler Ve Gerçekler, XV. Ulusal Yönetim ve Organizasyon Kongresi, Sakarya Üniversitesi.

Lin, A. C. (1998). Bridging Positivist and Interpretivist Approaches to Qualitative Methods. Policy Studies Journal, 26: 162-180.

Lincoln, Y. S., and Guba, E. G. (2000). Paradigmatic Controversies, Contradictions, and Emerging Confluences. in Denzin, N. K., and Lincoln, Y. S. Lincoln (Eds.), The Handbook of Qualitative Research (2nd ed., pp. 163-188), Thousand Oaks, CA: Sage Publications.

Mackenzie, N., and Knipe, S. (2006). Research Dilemmas: Paradigms, Methods and Methodology. Issues in Educational Research, 16 (2): 1-13.

McGregor, S. L. T., and Murnane, J. A. (2010). Paradigm, Methodology and Method: Intellectual Integrity in Consumer Scholarship. International Journal of Consumer Studies, 34: 419-427.

Mertens, D.M. (2005). Research Methods in Education and Psychology: Integrating Diversity with Quantitative and Qualitative Approaches. (2nd ed.) Thousand Oaks: Sage Publication.

Merton R. K. (1987). The Focused Interview and Focus Groups: Continuities and Discontinuities. The Public Opinion Quarterly, 51 (4): 550-566.

Molina-Azorín, J. F., and Font, X. (2016). Mixed Methods in Sustainable Tourism Research: An Analysis of Prevalence, Designs and Application in JOST (2005-2014). Journal of Sustainable Tourism, 24 (4): 549-573.

O'Leary, Z. (2004). The Essential Guide to Doing Research. London: Sage Publication.

Özdamar, K. (2002). Paket Programlarn ile İstatistiksel Veri Analizi (Çok Değişkenli Analizler) SPSSMINITAB 1, Eskişehir: Kaan Kitabevi.

Sale, J. E. M., and Brazil, K. (2004). A Strategy to Identify Critical Appraisal Criteria for Primary Mixed-Method Studies. Quality and Quantity, 38: 351-365.

Shah, S. K., and Corley, K. G. (2006). Building Better Theory by Bridging the QuantitativeQualitative Divide. Journal of Management Studies, 43: 1821-1835.

Singh, E., Milne, S., and Hull, J. (2012). Use of Mixed-Methods Case Study to Research Sustainable Tourism Development in South Pacific SIDS. Field Guide to Case Study Research in Tourism, Hospitality and Leisure (Advances in Culture, Tourism and Hospitality Research), 6: 457-478. 
Tutenges, S. (2012). Nightlife tourism: A Mixed Methods Study of Young Tourists at an International Nightlife Resort. Tourist Studies, 12 (2): 131-150.

Truong, D., Liu, R. X., and Yu, J. (2020). Mixed Methods Research in Tourism and Hospitality Journals. International Journal of Contemporary Hospitality Management, doi: 10.1108/IJCHM-032019-0286

Willis, J. W. (2007). Foundation of qualitative Research: Interpretative and Critical Approaches. Thousand Oaks, CA: Sage Publications.

Yıldırım, A. (1999). Nitel Araştırma Yöntemlerinin Temel Özellikleri ve Eğitim Araştırmalarındaki Yeri ve Önemi. Eğitim ve Bilim Dergisi, 23 (112): 7-17.

Yıldırım, A. ve Şimşek, H. (2016). Sosyal Bilimlerde Nitel Araştırma Yöntemleri. Ankara: Seçkin Yayıncilik.

Yüce, K., Eryaman, M. Y., Şahin, A. ve Koçer, Ö. (2014). Sosyal Bilimlerde Paradigma Dönüşümü ve Türkiye'de Uygulamalı Dilbilimi Alanında Nitel Araştırma. Eğitim ve Bilim, 39 (171): 1-12. 